\title{
Ancient Heat Shock Gene Is Dispensable
}

\author{
JAMES C. A. BARDWELL ${ }^{*}$ AND ELIZABETH A. CRAIG \\ Department of Physiological Chemistry, University of Wisconsin Medical School, Madison, Wisconsin 53706
}

Received 1 February 1988/Accepted 14 April 1988

\begin{abstract}
Hsp83 is a major eucaryotic heat shock protein and one of the most conserved proteins known. We have isolated an Escherichia coli gene homologous to eucaryotic Hsp83 and used it to construct a deletion mutation. The $E$. coli mutant was viable but had a slight growth disadvantage that increased with temperature.
\end{abstract}

Both eucaryotic and procaryotic cells respond to an upshift in growth temperature by strongly and rapidly inducing the synthesis of a small set of proteins. Synthesis of the heat shock proteins is also induced by viral infection and by treatment with ethanol, azide, arsenite, and certain other toxic chemicals; therefore, although the induction is more specific than a response to stress, it is more general than a response to heat alone (21). The number of proteins whose synthesis is induced varies in different species, but in all eucaryotic organisms studied, the major polypeptides include two highly conserved proteins of 83,000 and $70,000 M_{\mathrm{r}}$, called Hsp83 and Hsp70, respectively (15). Escherichia coli contains homologs to these two proteins. The $E$. coli protein DnaK is $50 \%$ identical to eucaryotic $\mathrm{Hsp} 70$ proteins (3), and the $E$. coli C62.5 heat shock protein is 41 and $42 \%$ identical to the Hsp83 proteins of Drosophila melanogaster and humans, respectively (4).

In addition to having an increased synthesis rate after a shift to high temperature, the $\mathrm{Hsp} 83$ protein is abundant in normal growth conditions, suggesting that it may play a role in normal metabolism (13). As a first step in addressing the role of this heat shock protein, we have deleted the htpG gene which codes for the $E$. coli $C 62.5$ protein. The htpG deletion mutant is viable but grows poorly at high temperatures.

\section{MATERIALS AND METHODS}

Bacterial and phage strains. The bacterial strains used in these experiments are identified in Table 1. Bacteriophage $\lambda h t p G^{+}$is a derivative of $\lambda \mathrm{gtWES}$. $\lambda \mathrm{C}$ (9) made by insertion of a 5.8-kilobase-pair Sall fragment carrying the htpG gene from $\mathrm{pBJ} 5$ into $\lambda \mathrm{gtWES} . \lambda \mathrm{C}$.

Plasmids. Deletion and insertion mutations of $h t p G$ were constructed in vitro. Plasmid pBJ7 contains a deletion mutation, and plasmid pBJ8 carries an insertion mutation.

In plasmid $\mathrm{pBJ} 7$, the htpG coding sequences have been replaced by $l a c Z$ coding sequences, creating a substitutiondeletion mutation of htpG called $\Delta h t p G l:: l a c Z$, and a kanamycin resistance $\left(\mathrm{Kan}^{r}\right)$ cassette has been inserted upstream of the htpG gene (Fig. 1). This plasmid was constructed in two stages. In the first stage, we inserted the $\mathrm{Kan}^{\mathrm{r}}$ cassette upstream of the $h t p G$ gene by (i) partially digesting plasmid $\mathrm{pBJ} 3$, which contains the BgIII-PstI fragment upstream from the htpG gene, with $\operatorname{Sau} 3 \mathrm{~A}$, so that on the average each plasmid had been cut once; (ii) isolating the $\mathrm{Kan}^{\mathrm{r}}$ cassette on a BamHI fragment from pUC-4K (26); (iii) ligating the pool of partially digested plasmids and the $\mathrm{Kan}^{\mathrm{r}}$

\footnotetext{
* Corresponding author.

$\dagger$ Present address: Frederick Cancer Research Facility, National Cancer Institute, Frederick, MD 21701-1013.
}

cassette; and (iv) screening by linear transformation among the resultant plasmids for one that had the $\mathrm{Kan}^{\mathrm{r}}$ cassette inserted into nonessential $E$. coli DNA. One plasmid, called $\mathrm{pBJ} 4$, that has the $\mathrm{Kan}^{\mathrm{r}}$ cassette inserted about 6.5 kilobase pairs upstream of the $h t p G$ gene, was selected for further manipulation.

In the second construction stage, the fusion between $h t p G$ and $l a c Z$ was made from plasmid pBJ5, which contains the SalI-SmaI fragment that includes the htpG gene and downstream flanking sequences. First, $h t p G$ coding sequences from the AluI site at codon 15 to the PvuII site at the third-to-last codon were deleted. This deletion recreates a $P v u I I$ site. Second, a promoterless lac $Z$ gene (derived from pMC1871 [6] by BamHI digestion and filling in the overhanging ends with the Klenow fragment of DNA polymerase) was inserted into this $P v u I I$ site. The resulting plasmid, pBJ6, had an in-frame fusion between the codons for amino acid 15 of C62.5 and amino acid 8 of $\beta$-galactosidase and has the coding sequences of $h t p G$ replaced with those of $l a c Z$. The deletion-substitution allele of $h t p G$ is called $\Delta h t p G l:: l a c Z$. Plasmid pBJ7, which contains both the $\mathrm{Kan}^{\mathrm{r}}$ cassette inserted into DNA upstream of the $h t p G$ gene and the $h t p G$ lac $Z$ fusion, was constructed by a third step that involved ligating the XbaI-PstI fragment from pBJ4 to the PstI-SalI fragment from $\mathrm{pBJ} 1$ and to the SalI-XbaI fragment from pBJ6. In all cases the cloning vector was pMT11, a pBR322 derivative obtained from $\mathrm{H}$. Huang and L. Hood (California Institute of Technology).

The insertion mutation in $h t p G$ was constructed as follows. A PstI-EcoRI subclone of $h t p G$ called $\mathrm{pBJ} 2$ was partially digested with Sau3A and ligated with the Kan cassette on a BamHI fragment from pUC-4K (26). One of the resulting plasmids, called pBJ8, had the $\mathrm{Kan}^{\mathrm{r}}$ fragment replacing the region of DNA encompassing codons 171 through 330 of the $h t p G$ gene. This disrupted, partially deleted allele of $h t p G$ is called $h t p G:: k a n-1122$.

Genetic manipulations. Linear transformation of DNA into a $\mathrm{RecB}^{-} \mathrm{RecC}^{-} \mathrm{SbcB}^{-}$strain was done as described by Winans et al. (28). Selection for lambda lysogens and P1 transductions were as described by Silhavy et al. (25). Selection for $\mathrm{Tet}^{\mathrm{s}}$ mutants by use of fusaric acid was as described by Maloy and Nunn (17). When necessary, the following antibodies were added: kanamycin sulfate $(100 \mu \mathrm{g} /$ $\mathrm{ml})$, tetracycline hydrochloride $(20 \mu \mathrm{g} / \mathrm{ml})$, and ampicillin $(100 \mu \mathrm{g} / \mathrm{ml})$. The $\mathrm{Lac}^{+/-}$phenotype was assayed either by including $10 \mu \mathrm{g}$ of 5-bromo-4-chloro-3-indolyl- $\beta$-D-galactoside (Xgal) per $\mathrm{ml}$ in solid medium or by spraying colonies with a $0.1 \%$ solution of 4 -methylumbelliferyl- $\beta$ - $D$-galactoside in $10 \%$ dimethyl sulfoxide. Methylumbelliferyl- $\beta$-D-galactoside is an analog of lactose that, when cleaved by 
TABLE 1. E. coli strains used

\begin{tabular}{|c|c|c|}
\hline Strain & Genotype" or phenotype & Source or reference \\
\hline BW360 & polAl zig-219::Tn10 & W. Wickner ${ }^{b}$ \\
\hline JC7623 & $\mathrm{AB} 1157$ recB21 recC22 sbcB15 sbcC201 & 4 \\
\hline MG1655 & $\mathbf{F}^{-}$ & $\mathrm{CGSC}^{c}$ \\
\hline MH594 & $\begin{array}{c}\mathrm{F}^{\prime} \text { pro lac } \Delta(\text { gpt-proAB-arg-lac)XIII } \\
\text { zaj::Tn } 10 \text { rpsL } \mathrm{His}^{-} \mathrm{Met}^{-} \mathrm{Nal}^{\mathrm{r}}\end{array}$ & C. Gross ${ }^{d}$ \\
\hline NK5661 & W3110 lacZ::Tn10 & W. Reznikoff ${ }^{d}$ \\
\hline AG1807 & $\mathrm{C} 600 \mathrm{GalK}^{-}$dnaG3 srl::Tn10 recA56 & C. Gross \\
\hline JB1 & JC7623 $\Delta$ (gpt-proAB-arg-lac)XIII zaj::Tn10 & $\mathrm{P} 1(\mathrm{MH} 594) \times \mathrm{JC} 7623 \rightarrow \mathrm{Tet}^{\mathrm{r}} ; \mathrm{Lac}^{-}$ \\
\hline JB2 & $\mathrm{JB} 1\left(\lambda h t p G^{+}\right)$ & This study \\
\hline JB3 & JB1 zba-315::kan & $\operatorname{Lin} \operatorname{Tr}(\mathrm{pBJ} 7) \times \mathrm{JB} 1 \rightarrow \mathrm{Kan}^{\mathrm{r}} ; \mathrm{Lac}^{-}$ \\
\hline JB4 & JB1 zba-315::kan $\Delta h t p G 1:: l a c Z$ & $\operatorname{Lin} \operatorname{Tr}(\mathrm{pBJ} 7) \times \mathrm{JB} 1 \rightarrow \mathrm{Kan}^{\mathrm{r}} ; \mathrm{Lac}^{+}$ \\
\hline JB5 & JB2 zba-315::kan & $\operatorname{Lin} \operatorname{Tr}(\mathrm{pBJ} 7) \times \mathrm{JB} 2 \rightarrow \mathrm{Kan}^{\mathrm{r}} ; \mathrm{Lac}^{-}$ \\
\hline JB6 & JB2 zba-315::kan $\Delta h t p G 1:: l a c Z$ & $\operatorname{LinTr}(\mathrm{pBJ} 7) \times \mathrm{JB} 2 \rightarrow \mathrm{Kan}^{\mathrm{r}} ; \mathrm{Lac}^{+}$ \\
\hline JB7 & JB1 zba-315::kan & $\mathrm{P} 1(\mathrm{JB} 23) \times \mathrm{JB} 1 \rightarrow \mathrm{Kan}^{\mathrm{r}} ; \mathrm{Lac}^{-}$ \\
\hline JB8 & JB1 zba-315::kan $\Delta$ htpG1::lacZ & $\mathrm{P} 1(\mathrm{JB} 23) \times \mathrm{JB} 1 \rightarrow \mathrm{Kan}^{\mathrm{r}} ; \mathrm{Lac}^{+}$ \\
\hline JB9 & JC7623 htpG::kan-I122 & $\operatorname{Lin} \operatorname{Tr}(\mathrm{pBJ} 8) \times \mathrm{JC7623} \rightarrow \mathrm{Kan}^{r}$ \\
\hline JB20 & MG1655 lacZ::Tn10 & P1(NK5661) $\times$ MG1655 $\rightarrow$ Tet $^{r} ;$ Lac $^{-}$ \\
\hline JB21 & $\mathrm{JB} 20\left(\lambda h t p G^{+}\right)$ & This study \\
\hline JB22 & JB20 zba-315::kan & $\mathrm{P} 1(\mathrm{JB6}) \times \mathrm{JB} 20 \rightarrow \mathrm{Kan}^{\mathrm{r}} ; \mathrm{Lac}^{-}$ \\
\hline JB23 & JB20 zba-315::kan $\Delta h t p G 1:: l a c Z$ & $\mathrm{P} 1(\mathrm{JB} 6) \times \mathrm{JB} 20 \rightarrow \mathrm{Kan}^{\mathrm{r}} ; \mathrm{Lac}^{+}$ \\
\hline JB24 & JB21 zba-315::kan & $\mathrm{P} 1(\mathrm{JB} 6) \times \mathrm{JB} 21 \rightarrow \mathrm{Kan}^{\mathrm{r}} ; \mathrm{Lac}^{-}$ \\
\hline JB25 & JB21 zba::kan $\Delta$ htpGl::lacZ & $\mathrm{P} 1(\mathrm{JB} 6) \times \mathrm{JB} 21 \rightarrow \mathrm{Kan}^{\mathrm{r}} ; \mathrm{Lac}^{+}$ \\
\hline JB40 & MG1655 $\Delta$ (gpt-proAB-arg-lac)XIII zaj::Tn10 & P1(MH594) $\times$ AB1157 $\rightarrow$ Tet $^{r} ;$ Lac $^{-}$ \\
\hline JB41 & JB40 zba-3i5::kan & $\mathrm{P} 1(\mathrm{JB} 23) \times \mathrm{JB} 40 \rightarrow \mathrm{Kan}^{\mathrm{r}} ; \mathrm{Lac}^{-}$ \\
\hline JB42 & JB40 zba-315::kan $\Delta$ htpGl::lacZ & $\mathrm{P} 1(\mathrm{JB} 23) \times \mathrm{JB} 40 \rightarrow \mathrm{Kan}^{\mathrm{r}} ; \mathrm{Lac}^{+}$ \\
\hline JB43 & MG1655 lacZ::Tn10 Tet $^{\mathrm{s}}$ & $\mathrm{JB} 20 \rightarrow \mathrm{Tet}^{\mathrm{s}}$ by fusaric acid \\
\hline JB44 & JB43 zba-315::kan & $\mathrm{P} 1(\mathrm{JB} 23) \times \mathrm{JB} 43 \rightarrow \mathrm{Kan}^{\mathrm{r}} ; \mathrm{Lac}^{-}$ \\
\hline JB45 & JB43 zba-315::kan $\Delta h t p G l:: l a c Z$ & $\mathrm{P} 1(\mathrm{JB} 23) \times \mathrm{JB} 43 \rightarrow \mathrm{Kan}^{\mathrm{r}} ; \mathrm{Lac}^{+}$ \\
\hline JB46 & JB44 $s r l:: \operatorname{Tn} 10$ & P1(AG1807) $\times$ JB44 $\rightarrow$ Tet $^{r} ; U^{r}$ \\
\hline JB47 & JB44 $s r l:: \operatorname{Tn} 10$ recA56 & $\mathrm{P} 1(\mathrm{AG} 1807) \times \mathrm{JB} 44 \rightarrow \mathrm{Tet}^{\mathrm{r}} ; \mathrm{UV}^{\mathrm{s}}$ \\
\hline JB48 & JB45 srl::Tn10 & $\mathrm{P} 1$ (AG1807) $\times \mathrm{JB} 45 \rightarrow \mathrm{Tet}^{\mathrm{r}} ; \mathrm{UV}^{\mathrm{r}}$ \\
\hline JB49 & JB45 srl::Tn10 recA56 & $\mathrm{P} 1(\mathrm{AG} 1807) \times \mathrm{JB} 45 \rightarrow$ Tet $^{\mathrm{r}} ; \mathrm{UV}^{\mathrm{s}}$ \\
\hline JB50 & JB44 zig-219::Tn10 & $\mathrm{P} 1(\mathrm{BW} 360) \times \mathrm{JB} 44 \rightarrow$ Tet $^{\mathrm{r}} ; \mathrm{MMS}^{\mathrm{r}}$ \\
\hline JB51 & JB44 zig-219::Tn10 polAl & $\mathrm{P} 1(\mathrm{BW} 360) \times \mathrm{JB} 44 \rightarrow \mathrm{Tet}^{\mathrm{r}} ; \mathrm{MMS}^{\mathrm{s}}$ \\
\hline JB52 & JB45 zig-219::Tn10 & $\mathrm{P} 1(\mathrm{BW} 360) \times \mathrm{JB} 45 \rightarrow$ Tet $^{\mathrm{r}} ; \mathrm{MMS}^{\mathrm{r}}$ \\
\hline JB53 & JB45 zig-219::Tn10 polAl & P1(BW360) $\times$ JB45 $\rightarrow$ Tet $^{r} ;$ MMS $^{s}$ \\
\hline
\end{tabular}

${ }^{a}$ For gene symbols, see reference 1. Phenotype symbols were derived from gene symbols except as follows: Tet, tetracycline; Kan, kanamycin; Nal, nalidixic acid; MMS, methyl methanesulfonate. $r$, Resistance; s, sensitivity. P1 tranductions (P1) are described as follows: P1(donor strain) $\times$ recipient $\rightarrow$ selected phenotype; screened phenotype. Linear transformations (LinTr) are described as follows: $\operatorname{Lin} \operatorname{Tr}($ plasmid name) $\times$ recipient $\rightarrow$ selected phenotype; screened phenotype.

${ }^{b}$ University of California, Los Angeles.

c CGSC, E. coli Genetic Stock Center, Yale University, New Haven, Conn.

${ }^{d}$ University of Wisconsin, Madison.

$\beta$-galactosidase, fluoresces a bright blue under UV illumination.

DNA and protein methods. Agarose gel electrophoresis and nick translation were as previously described (3). Southern blots were hybridized to ${ }^{32} \mathrm{P}$-labeled DNA probes under very nonstringent conditions $(30 \%$ formamide, $0.75 \mathrm{M} \mathrm{NaCl}$ at $37^{\circ} \mathrm{C}$ ) as previously described (3). Radioactive labeling of bacterial heat shock proteins with $\left[{ }^{35} \mathrm{~S}\right]$ methionine was as previously described (19). Heat shock proteins were identified on two-dimensional O'Farrell gels (22) as described by Neidhardt et al. (20).

Measurement of maximal growth temperature. A temperature gradient incubator was constructed as described by Landman et al. (14). The incubator was made of two sheets of aluminum ( 30 by 60 by $0.7 \mathrm{~cm}$ ). Heat was supplied at one end by contact to a Lab-Line Multi-Temp-Blok heater. The

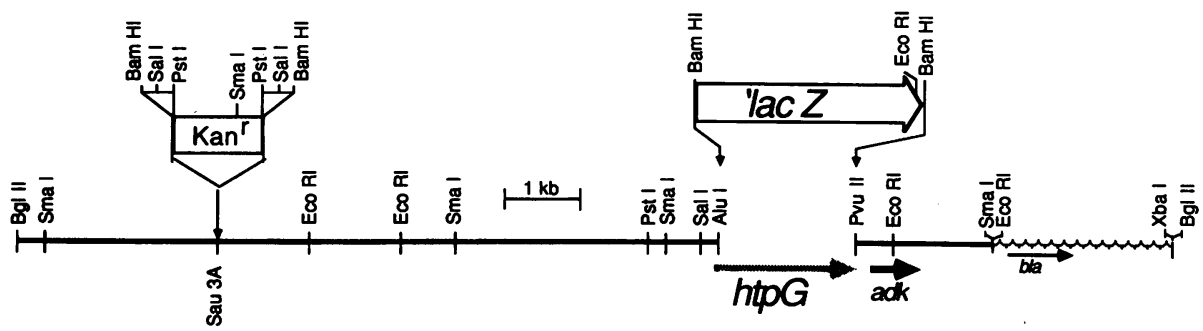

FIG. 1. Linearized restriction map of pBJ7, the plasmid used for deleting the htpG gene. In this plasmid, a Kan cassette was inserted upstream from $h t p G$ and the $h t p G$ gene was replaced with the $l a c Z$ gene. pBR322-derived sequences are shown as a wavy line. Only the $A l u I$, Sau3A, and PvuII sites used in plasmid construction are shown. 


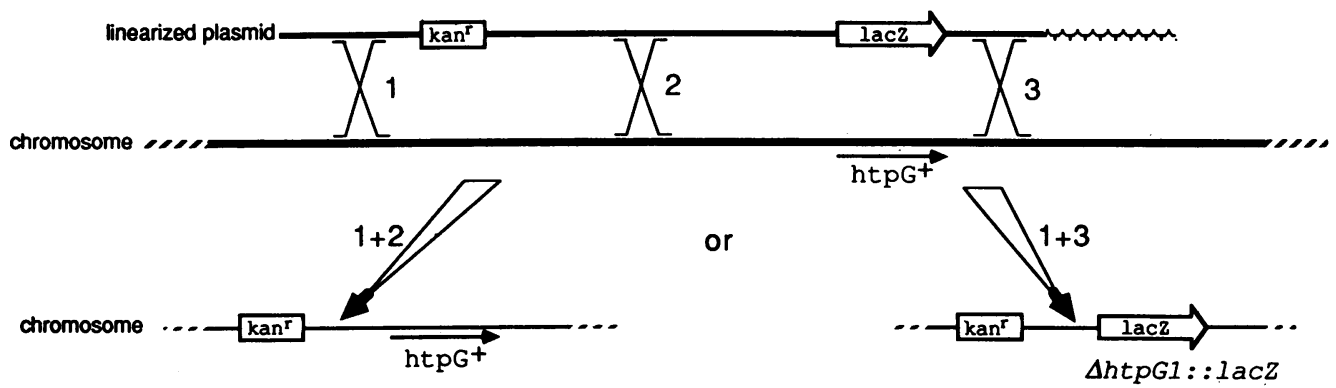

FIG. 2. Schematic diagram of the recombination events required for the replacement of the chromosomal htpG $G^{+}$allele with the lac substitution mutation $\Delta h t p G 1:: l a c Z$. Linearized plasmid pBJ7 DNA was transformed into JB1 and JB2 $\left(\lambda h t p G^{+}\right)$, with selection for Kan ${ }^{r}$ transformants. Either of two homologous recombination events can result in the insertion of the Kan ${ }^{r}$ marker from the plasmid to the chromosome. If crossovers 1 and 2 occur, $\mathrm{a} \mathrm{Kan}^{\mathrm{r}} h t p G^{+}$recombinant results. If, however, crossovers 1 and 3 occur, Kan ${ }^{\mathrm{r}} \Delta h t p G l:: l a c Z$ recombinant results. Solid lines represent $E$. coli DNA, the wavy line represents vector sequences.

heat was dissipated along the length of the metal so that a temperature gradient was produced. Cookie sheets ( 24 by 33 $\mathrm{cm}$ ) containing 1 liter of brain heart infution agar (Difco Laboratories) were used as large petri plates. These petri plates were sandwiched between the two slabs of the temperature gradient incubator and prewarmed. Cultures to be tested were swabbed down the temperature gradient formed along the length of the plate. A growth front developed at the maximal growth temperature of the bacteria. Temperature was periodically monitored at various points along the gradient by a thermistor connected to a Hewlett-Packard 3421A data acquisition unit. This temperature-recording device is accurate to $0.01^{\circ} \mathrm{C}$.

\section{RESULTS}

Experimental rationale. The $\mathrm{C} 62.5$ heat shock protein of $E$. coli is homologous to the Hsp83 protein of eucaryotes. We sought to analyze the function of the C62.5 protein in $E$. coli by studying the effect of its absence. To do this, we substituted the chromosomal copy of the $h t p G$ gene, which codes for C62.5, with lacZ sequences. This substitution was carried out in two strains, one haploid for $h t p G$ and the other containing a second copy of the wild-type $h t p G$ gene, in case the loss of the C62.5 protein was lethal.

In vitro mutagenesis of the $h t p G$ gene. The mapping of $h t p G$ suggested that it is a newly identified gene (4). Because the function of $\mathrm{Hsp} 83$ is not known and because there are no previously characterized mutations in $h t p G$, we decided to mutate the $h t p G$ locus in vitro and transfer the mutation onto the $E$. coli chromosome. The first step in the isolation of $h t p G$ null mutants was to construct a plasmid that carried a deletion mutation in $h t p G$. The $h t p G$ deletion mutation $\Delta h t p G 1$ ::lac $Z$ was made by removing all but 18 codons of the C62.5-coding region and replacing them with $\beta$-galactosidase protein-coding sequences (Fig. 1). This construction created a protein fusion between $\mathrm{C} 62.5$ and $\beta$-galactosidase that yields a screenable $\mathrm{Lac}^{+}$phenotype for the $h t p G$ deletion. DNA containing a drug resistance marker from the transposon Tn903, conferring $\mathrm{Kan}^{\mathrm{r}}$, was inserted into flanking DNA 8 kilobase pairs upstream of this substitution mutation. This provided a linked, selectable $\mathrm{Kan}^{\mathrm{r}}$ marker for transferring the $\Delta$ tp $G 1:: l a c Z$ null allele into the chromosome. The plasmid containing the $\Delta h t p G 1:: l a c Z$ mutation and the linked $\mathrm{Kan}^{\mathrm{r}}$ marker was called pBJ7 (Fig. 1).

Replacement of the chromosomal $h t p G^{+}$locus with the $h t p G$ deletion mutation. The in vitro-mutated copy of $h t p G$ was transferred into the $E$. coli chromosome by linear transfor- mation (28), a one-step gene replacement technique similar to the method of Rothstein used for yeast cells (24). The plasmid pBJ7 was linearized and transformed into a pair of strains, JB1 and JB2. JB1 is haploid for htpG, while JB2 contains a second copy of $h t p G$ on a lambda clone integrated at the $\lambda$ att site. Both strains are deleted for the lac $Z$ gene, which allowed screening for the $\mathrm{Lac}^{+}$phenotype of the $\Delta h t p G 1:$ :lacZ substitution mutation, and $\mathrm{RecBC}^{-} \mathrm{SbcB}^{-}$, which allowed for linear transformation (28). After transformation, $\mathrm{Kan}^{\mathrm{r}}$ colonies were selected and the proportion of these that were $\mathrm{Lac}^{+}$(and therefore had htpG deleted) was determined. The selection in these transformations was for a marker $\left(\mathrm{Kan}^{\mathrm{r}}\right)$ genetically linked to the $\Delta h t p G l:: l a c Z$ mutation but not for the deletion itself (Fig. 2). The prediction was that if the htpG gene was essential, we would be able to recover transformants of the deletion in the merodiploid but would be unable to delete the $h t p G$ gene from the haploid.

The insertion of the $\mathrm{Kan}^{\mathrm{r}}$ marker into the chromosome near htpG requires a homologous recombination event on each side of the $\mathrm{Kan}^{\mathrm{r}}$ cassette. Recombination of the linearized DNA with the chromosome could occur in either of two ways to produce a $\mathrm{Kan}^{\mathrm{r}}$ recombinant (Fig. 2). The first pair of crossovers would yield a $\mathrm{Lac}^{-}$transformant with an intact $h t p G$ gene. If the second pair of crossovers occurred, the resulting strain would have the $h t p G$ structural gene replaced with the lac $Z$ substitution mutation. It would therefore be $\mathrm{Lac}^{+}$and $h t p G$ deleted. If $\mathrm{C} 62.5$ was essential, $\mathrm{Lac}^{+}$colonies would be found only upon transformation of the merodiploid.

Similar proportions of $\mathrm{Kan}^{\mathrm{r}} \mathrm{Lac}^{+}$transformants, which had the $h t p G$ gene deleted, were recovered from parallel transformations into the $h t p G$ haploid and merodiploid, suggesting that the $h t p G$ gene is not essential for normal $E$. coli growth. Of the $\mathrm{Kan}^{\mathrm{r}}$ colonies, $29 \%$ (29 of 101) were $\mathrm{Lac}^{+}$ after transformation of the haploid and $19 \%$ (24 of 129) were $\mathrm{Lac}^{+}$after transformation of the $h t p G$ merodiploid. Similar results were obtained after transducing the $\mathrm{Kan}^{\mathrm{r}}$ marker with phage $\mathrm{P} 1$ into $\mathrm{Lac}^{-}$but otherwise wild-type strains. A P1-transducing lysate was prepared on a strain (JB6) merodiploid for the $h t p G$ deletion. This lysate was used to transduce the wild-type strains JB20 (htpG haploid) and JB21 ( $h t p G$ merodiploid) to $\mathrm{Kan}^{\mathrm{r}}$. The $h t p G$ deletion was 66 to $68 \%$ linked to $\mathrm{Kan}^{\mathrm{r}}$ in transductions into both JB20 (223 of $332 \mathrm{Kan}^{\mathrm{r}}$ transductants were $\mathrm{Lac}^{+}$) and JB21 (247 of 360 were $\mathrm{Lac}^{+}$).

Characterization of the $h t p G$ deletion mutation. We demonstrated that the htpG gene was deleted from the haploid $\mathrm{Lac}^{+}$transformants (JB4) and transductants (JB23) by low- 


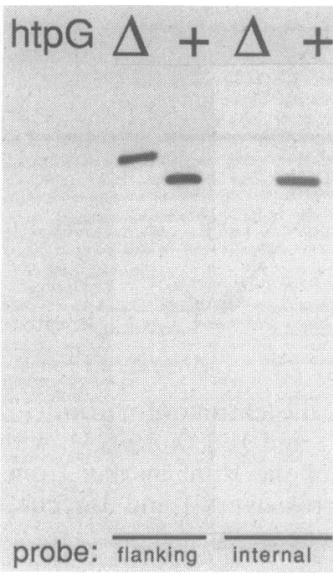

FIG. 3. Southern hybridization analysis of the $\Delta h t p G l:: l a c Z$ mutant Sma I-digested chromosomal DNAs from strains JB22 $\left(h t p G^{+}\right)(+)$and JB23 $(\Delta h t p G 1:: \operatorname{lacZ})(\Delta)$ were hybridized to a ${ }^{32}$ P-labeled DNA fragment either internal to or flanking the $h t p G$ gene. The internal probe encompassed the codons for amino acids 93 to 621 of $h t p G$. The flanking probe was a DNA fragment containing the 356 base pairs just downstream of the $h t p G$ gene.

stringency Southern blotting (Fig. 3 and data not shown). When probes from the protein-coding region of the htpG gene encompassing amino acids 30 through 621 were hybridized to DNA of the htpG substitution strain, no strong hybridization was observed (Fig. 3 and data not shown). Flanking probes hybridized to a DNA fragment in the substitution strain that was larger than the fragment present in the wild-type strain.

To show that the $\mathrm{C} 62.5$ protein was not synthesized in the deletion strain, the proteins synthesized by the haploid $h t p G$ deletion strain JB23 and by the $\mathrm{Kan}^{\mathrm{r}} h t p G^{+}$control strain JB22 were separated on two-dimensional gels (Fig. 4). The C62.5 protein was missing from the deletion strain. The new spot observed was the size and position predicted for the C62.5- $\beta$-galactosidase fusion protein. No other major differences in protein synthesis pattern between these two strains were consistently observed. Therefore, we did not detect the induction of synthesis of any proteins that might compensate for the absence of C62.5 synthesis. Furthermore, protein

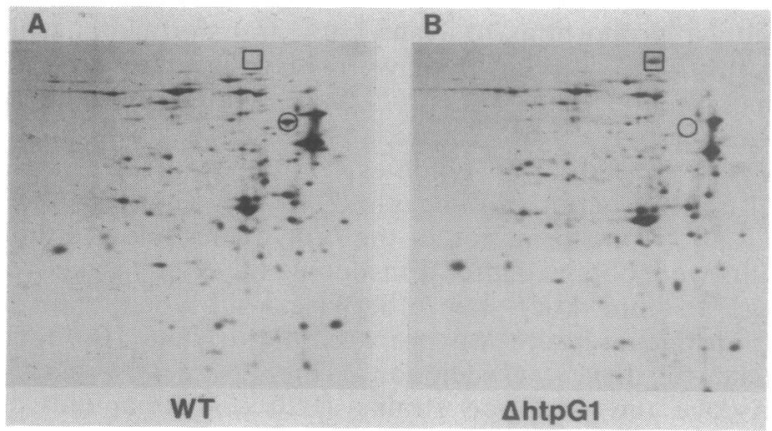

FIG. 4. Two-dimensional gels showing the absence of the C62.5 protein in the htpG deletion strain. Wild-type (WT) strain JB22 (A) and $\Delta$ tp $1::$ lacZ strain JB23 (B) were heat shocked at $43^{\circ} \mathrm{C}$ and labeled with $\left[{ }^{35}\right.$ S $]$ methionine. Labeled proteins were resolved on two-dimensional gels. The position of the C62.5 protein is circled, and the position of the $\mathrm{C} 62.5-\beta$-galactosidase fusion protein is boxed.
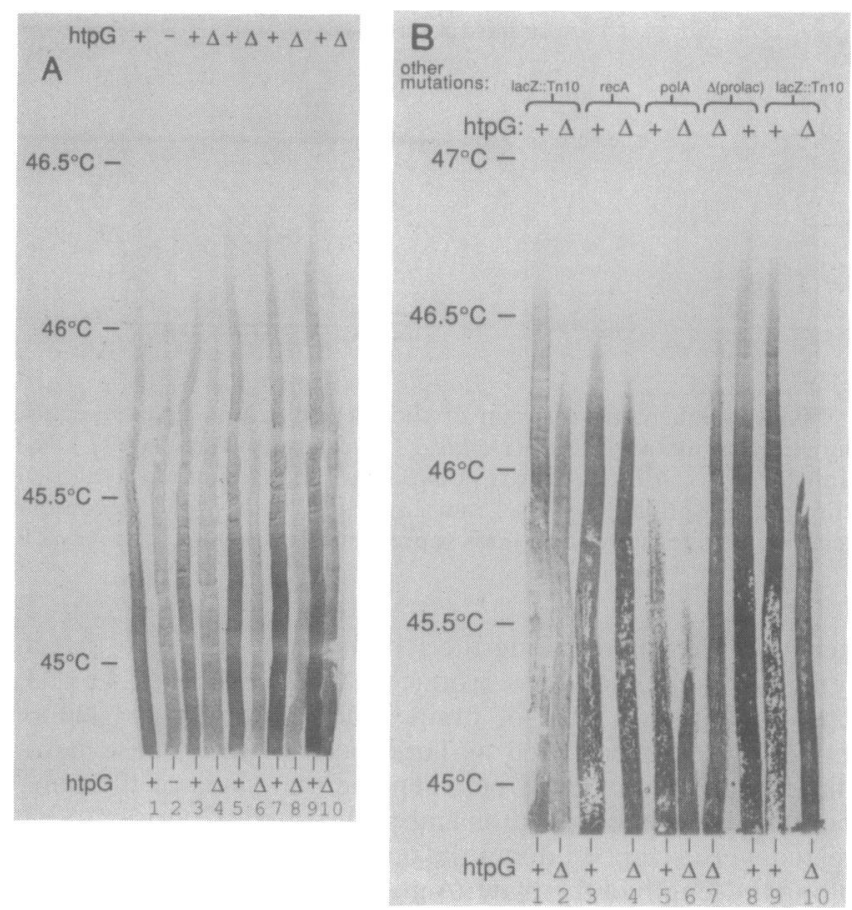

FIG. 5. Comparison of the maximal growth temperatures of htpG null mutant and isogenic wild-type control strains. A brain heart infusion agar plate was swabbed with overnight cultures of different independent transformants of a $\Delta h t p G l:: l a c Z$ mutant or of the corresponding $h t p G^{+}$control strain and placed in a temperature gradient incubator as described in Materials and Methods. A growth front appears at the maximal growth temperature of each strain. The indicated temperatures fluctuated by less than $0.05^{\circ} \mathrm{C}$ over the course of the experiment. To clearly visualize bacterial growth, the temperature gradient plate was replica plated onto Whatman $3 \mathrm{MM}$ filter paper and the bacteria were stained with $0.1 \%$ Coomassie blue. (A) Temperature gradient plate of $h t p G$ mutants in the JC7623 background. The lanes alternate $h t p G^{+}$and $\Delta h t p G(\Delta)$ strains except lane 2, which shows an insertion mutation in htpG called htpG::kan1122 (-). Lanes: 1, parent strain JC7623; 4, 6, 8, and 10 , $\Delta$ tp $G l:: l a c Z$ strain JB8; 3, 5, 7, and 9, isogenic htp $G^{+}$control strain JB7. (B) Temperature gradient plate of strains carrying the htpG deletion in combination with other mutations in the MG1655 background. Lanes: 1 and 9, JB22; 2 and 10, JB23; 3, JB47; 4, JB49; 5 , JB51; 6, JB53; 7, JB42; 8, JB41. The control strains JB20, JB22, JB43, JB46, and JB50, which contained only $\mathrm{Tn} 10$ or $\mathrm{Kan}^{\mathrm{r}}$ insertions or both, all had a maximal growth temperature identical to that of their MG1655 parent (not shown).

samples prepared from the htpG deletion fail to react on Western blots (immunoblots) with a polyclonal antibody made against purified C62.5 protein (J. Spence and C. Georgopoulos, personal communication). The absence of cross-reacting protein in the deletion strain and the absence of hybridization to DNA of the deletion by probes from either the htpG gene or the Drosophila hsp83 gene show that there is only one copy of the $h t p G$ gene. This also suggests that there are no other genes or proteins with extensive homology to C62.5.

$h t p G$ deletion strain is slightly temperature sensitive. The $h t p G$ deletion strain JB8 was found to grow more poorly at high temperatures than the isogenic control strain, JB7, which contains just the $\mathrm{Kan}^{\mathrm{r}}$ insertion. Figure 5A shows the growth of these bacteria on a thermal gradient agar plate whose temperature range encompassed the maximal growth temperatures of these strains. $\mathrm{HtpG}^{+}$and $\mathrm{HtpG}^{-}$transduc- 
tants were swabbed next to each other. A comparison of lanes $4,6,8$, and 10 ( $\Delta$ htpGl::lacZ) with lanes $3,5,7$, and 9 ( $h t p G^{+}$control) of Fig. 5A shows that the temperature sensitivity contransduced with the deletion. To determine whether the poor growth at high temperatures was due to overproduction of the C62.5- $\beta$-galactosidase fusion protein and not due to the deletion of $h t p G$, we constructed a Kan ${ }^{\mathrm{r}}$ insertion mutation in htpG called htpG::kan-1122. After linear transformation into the $E$. coli chromosome, it caused the same phenotype as did the lac $Z$ substitution $\Delta$ tp $G 1:$ :lacZ mutation (Fig. 5A, compare lanes 2 and 4). The deletion and insertion mutants both grow more poorly at temperatures slightly below their maximum.

When the $h t p G$ deletion was transduced into the wild-type MG1655 strain background, it again caused a reduction in the maximal growth temperature (Fig. 5B, compare lanes 1 and 2). Although the temperature sensitivity cotransduced with the $\Delta h t p G l:: l a c Z$ mutation into all different strain backgrounds tested (Fig. 5B and data not shown), it appeared to be most severe in the JC7623 background.

$h t p G$ deletion strain has a growth disadvantage. To determine whether the $\mathrm{HtpG}^{+}$phenotype conferred a selective advantage of $E$. coli cells of the wild-type MG1655 background growing under optimal conditions, equal volumes of log-phase cultures of JB22 ( $\left.h t p G^{+}\right)$and JB23 ( $\Delta$ htpGl::lacZ) cells were combined and grown in mixed culture in the log phase for many generations at various temperatures. When the cells were grown at $37^{\circ} \mathrm{C}$, the proportion of $h t p G$-deleted cells fell slowly. After 400 generations of growth at $37^{\circ} \mathrm{C}$, the wild-type cells outnumbered the deletion cells by a ratio of 3 : 1 (Fig. 6A). This suggests that the $h t p G$ deletion strain is not as fit as the wild-type strain. When the same experiment was performed at $46^{\circ} \mathrm{C}$, the deletion strain was more quickly lost from the mixed culture. After 100 generations of growth at $46^{\circ} \mathrm{C}$, the wild-type cells outnumbered the deletion cells by a ratio of greater than $10: 1$. At $46.5^{\circ} \mathrm{C}$ the $h t p G$ deletion strain was lost after only a few generations of growth.

The competition experiment was repeated at $37^{\circ} \mathrm{C}$ in the multiply marked JC7623 background. In this background, the $\Delta h t p G l:: l a c Z$ deletion strain was quickly outgrown in the mixed culture even at $37^{\circ} \mathrm{C}$ (compare Fig. 6A and B [note difference in scale]). Since the $\Delta h t p G l:: l a c Z$ strain was outgrown so quickly at $37^{\circ} \mathrm{C}$, we determined the growth rate at a high temperature to determine whether major growth differences could be observed in unmixed cultures. At $44^{\circ} \mathrm{C}$ in the JC7623 background, the control strain JB7 grew with a doubling time of $32 \mathrm{~min}$. The $\Delta$ htpGl::lacZ strain JB8 had a doubling time of $53 \mathrm{~min}$ and leveled off at a lower optical density (Fig. 7). This slower growth rate of the $\Delta$ th $G 1$ ::lac $Z$ strain JB8 at high temperatures could also be observed on temperature gradient plates as fainter growth (Fig. 5A) and on petri dishes as smaller colonies.

It has not been determined which mutation (or mutations) in the JC7623 background exaggerate the growth disadvantage of the $\Delta h t p G l:: l a c Z$ mutation. Other mutations that make $E$. coli less fit, such as rec $A 56$ or polA $I$, also decrease the maximal growth temperature of the bacteria but do not appear to act synergistically with the $\Delta h t p G l:: l a c Z$ mutation (Fig. 5B). Not all mutations decrease the maximal growth temperature of $E$. coli; the $\Delta($ gpt-proAB-argF-lac $)$ XIII deletion, which removes $\sim 400$ kilobase pairs of the $E$. coli chromosome (1), does not cause a reduction in the maximal growth temperature (compare lanes 8 and 9 of Fig. 5B or lanes 1 and 3 of Fig. 5A).
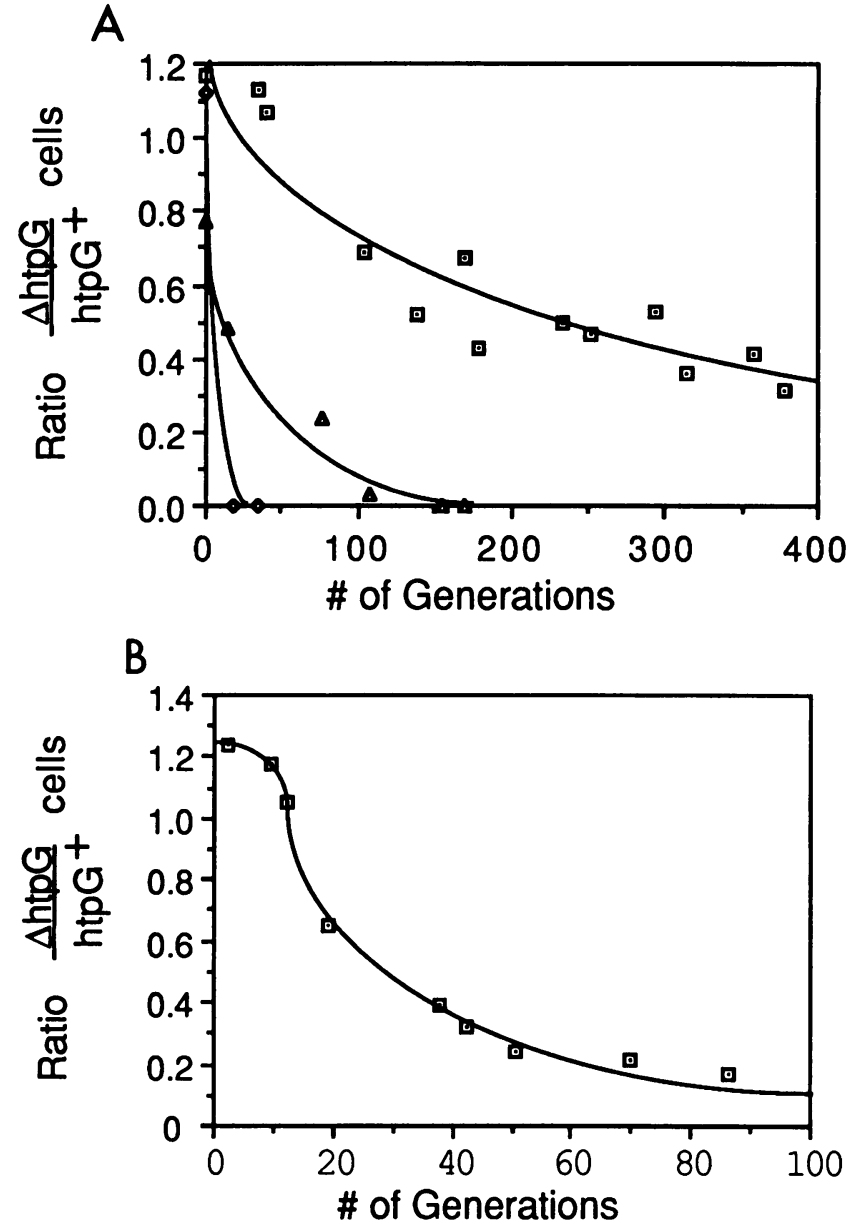

FIG. 6. Growth competition experiment. Equal volumes of logphase cultures (optical density at $600 \mathrm{~nm} ; 0.2$ ) of $h t p G^{+}$and $\Delta$ htpGl::lacZ mutants were combined, diluted 1:1,000, and grown at various temperatures in mixed culture. The cultures were maintained in $\log$ phase by repeatedly diluting each culture $1: 100,000$ into fresh prewarmed $\mathrm{L}$ broth before the culture reached an optical density at $600 \mathrm{~nm}$ of 0.4 . The proportion of the $\Delta h t p G l:: l a c Z$ mutant cells was monitored by plating appropriate dilutions of the cultures at various times and determining the fraction of $\mathrm{Lac}^{+}$cells. (A) Growth competition in the MG1655 background. The $\Delta h t p G:: l a c Z$ strain used was JB23, and the isogenic wild-type control was JB22. The cultures were grown at $37^{\circ} \mathrm{C}(\bullet), 46^{\circ} \mathrm{C}(\triangle)$, or $46.6^{\circ} \mathrm{C}(\diamond)$. (B) Growth competition in the JC7623 background at $37^{\circ} \mathrm{C}$. The $\Delta$ tpGl::lac $Z$ strain used was JB7; the isogenic htp $G^{+}$control was JB8.

\section{DISCUSSION}

We have shown previously that $E$. coli contains a single gene, called $h t p G$, that is homologous to the $h s p 83$ gene of eucaryotes (4). The present study was designed to determine whether the protein encoded by this gene is essential for cell growth. We constructed and characterized an $E$. coli strain with a deletion of the $h t p G$ gene. The mutation reduces the reproductive fitness and the maximal growth temperature of $E$. coli. These phenotypes are not likely to be due to a polar effect on the $a d k$ gene, which is immediately downstream from $h t p G$, since the lacZ-substituted $h t p G$ deletion mutation was designed to be nonpolar and since the following evidence suggests that the $a d k$ gene is expressed from its own promoter. First, $a d k$ is not in the heat shock regulon, 


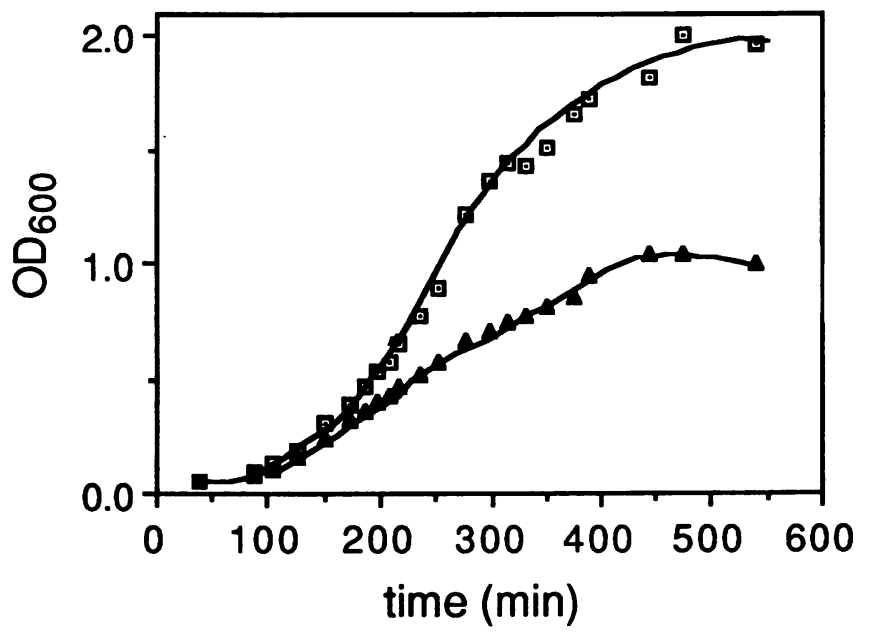

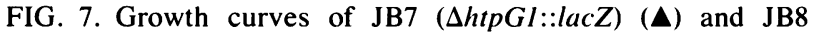
$\left(h t p G^{+}\right)(\square)$ at $44^{\circ} \mathrm{C}$. Samples were removed at the indicated times, and the optical density of the culture at $600 \mathrm{~nm}\left(\mathrm{OD}_{600}\right)$ was determined.

and the $a d k$ product, adenylate kinase, is more abundant than the C62.5 protein (R. A. VanBogelen, T. A. Phillips, and F. C. Neidhardt, personal communication). Second, in the 1980 base pairs between the termination codon for htpG and the initiation codon of $a d k$, there is a potential Rhoindependent terminator site (4). Third, upstream of $a d k$, there is a close match with the $E$. coli $\sigma^{70}$ promoter consensus (4). Fourth, a pBR322 clone of the $a d k$ gene that does not contain the htpG promoter overexpresses the adk gene product, adenylate kinase, 20 -fold (5). This evidence suggests that the $a d k$ gene is transcribed from its own promoter. We conclude that the poor growth of the htpG deletion and insertion mutants observed at high temperature is a result of the absence of the C62.5 heat shock protein.

The htpG deletion did not require complementation by $h t p G^{+}$for viability. This result is unexpected, because Hsp83 is one of the most conserved proteins known and because it has been shown that the $h s p 83$ genes encode an essential function in yeast cells. Yeast cells contain two copies of the $h s p 83$ gene which encode proteins $>96 \%$ homologous to each other. One gene is a heat shock gene, while the other is constitutively expressed. Strains containing insertion mutations in either gene were viable, but strains with insertions in both genes were not viable (F. W. Farrelly, and D. A. Finkelstein, Fed. Proc. 43:1499, 1984).

We have examined the possibility that $h t p G$ encodes an essential function but that there are multiple copies of related genes in $E$. coli that encode proteins with compensating activities. Attempts to find a second gene or protein related to $h t p G$ or C62.5 by using DNA and antibody probes have been unsuccessful, but the level of homology may be undetectable by these methods. It is not clear how much amino acid homology between two proteins is needed for their genes to cross-hybridize, but hybridization between the $r p o H$ and $r p o D$ genes, whose products show $23 \%$ amino acid identity, can be detected on genomic Southern blots by using our conditions (unpublished observations). Therefore, if there is a protein whose function overlaps that of C62.5, it is unlikely that it is closely related.

Since $h t p G$ deletion and insertion strains were more sensitive than wild-type strains to heat, we asked whether the deletion strain was more sensitive to other inducers of the heat shock response. A rapid screening method was devised to find chemicals that induce the $h t p G$ promoter and to determine whether the htpG deletion strain is more sensitive to these chemicals than is a wild-type control strain (J. C. A. Bardwell, Ph.D. thesis, University of Wisconsin, Madison, 1987). Of the 256 chemicals screened, 36 were found to have a strong effect on $h t p G$ expression. No large differences in sensitivity to any of the chemicals tested were detected between the wild-type strain and the $h t p G$ deletion mutant. UV irradiation and bacteriophage lambda infection are also known to induce the expression of the heat shock proteins $(8,12)$. The $h t p G$ deletion strain shows no change in its resistance to UV irradiation (data not shown) and plates the bacteriophage lambda with an efficiency of 1 .

We had previously mapped htpG to $11.1 \mathrm{~min}$ on the $E$. coli chromosome. We excluded the possibility that $h t p G$ is allelic to any of the known genes in the region, with the possible exception of ras and hemH, for which strains containing characterized mutations no longer exist. It seems unlikely, however, that $h t p G$ is allelic to hemH or ras, since the htpG deletion and insertion mutants do not display the UV sensitivity of the ras mutant (27) or the red pigmentation of the hemH mutant (7).

$E$. coli mutants defective in the induction of heat shock protein synthesis are defective in proteolysis $(2,10)$. The lon gene, which encodes an ATP-dependent protease, is a heat shock gene, and a strain carrying a deletion mutation in lon is defective in proteolysis $(18,23)$. Amino acid analogs are known to induce synthesis of some of the heat shock proteins (21). These facts have led to the suggestion that some of the heat shock proteins may be involved in degradation of unstable proteins. C62.5 does not appear to be one of these, since the $h t p G$ deletion mutant has a normal rate of degradation of unstable puromycyl peptides (W. Walter, D. Straus, and C. Gross, personal communication).

Strains carrying insertion and deletion mutations in the htp $G$ gene were found to be slightly temperature sensitive. This may reflect the (yet undefined) role of the heat shock proteins in promoting growth at high temperatures. However, in addition it was found that $h t p G^{+}$provided a growth advantage to cells grown under optimal conditions. This advantage and relative abundance of the $\mathrm{C} 62.5$ protein (under normal conditions, C62.5 makes up $0.45 \%$ of cell protein by mass at $37^{\circ} \mathrm{C}$ [11]) suggest that C62.5 plays an important role in normal growth. The evolutionary advantage provided by $h t p G^{+}$is probably sufficient to explain why the protein has been maintained for 2 billion years. The mechanism behind the growth disadvantage of the htpG null mutants remains to be elucidated.

\section{ACKNOWLEDGMENTS}

We are grateful to $C$. Gross and the members of her laboratory for helpful discussion on this work. We thank B. Bachmann for bacterial strains. We thank $\mathrm{K}$. Tilly for assistance in computer modeling of the vector sequences in Fig. 1 and 2. We also thank K. Tilly, J. Doctor, and D. Court for critically reading the manuscript.

This work was supported by Public Health Service grant GM72870 to E.A.C. from the National Institutes of Health.

\section{LITERATURE CITED}

1. Bachmann, B. J. 1983. Linkage map of Escherichia coli K-12, edition 7. Microbiol. Rev. 47:180-230.

2. Baker, T. A., A. D. Grossman, and C. A. Gross. 1984. A gene regulating the heat shock response in $E$. coli also causes a defect in proteolysis. Proc. Natl. Acad. Sci. USA 81:6779-6783.

3. Bardwell, J. C. A., and E. A. Craig. 1984. Major heat shock gene of Drosophila and the Escherichia coli heat inducible dnaK gene 
are homologous. Proc. Natl. Acad. Sci. USA 81:848-852.

4. Bardwell, J. C. A., and E. A. Craig. 1987. Eukaryotic Mr-83,000 heat shock protein has a homologue in Escherichia coli. Proc. Natl. Acad. Sci. USA 84:5177-5181.

5. Brune, M., R. Schumann, and F. Wittinghofer. 1985. Cloning and sequencing of the adenylate kinase gene $(a d k)$ of Escherichia coli. Nucleic Acids Res. 13:7139-7151.

6. Casadaban, M. J., A. Martinez-Arias, S. K. Shipira, and J. Chou. 1983. $\beta$-Galactosidase gene fusions for analysing gene expression in Escherichia coli and yeast. Methods Enzymol. 100:293-308.

7. Cox, R., and H. P. Charles. 1973. Porphyrin-accumulating mutants of Escherichia coli. J. Bacteriol. 113:122-132.

8. Drahos, D. J., and R. W. Hendrix. 1982. Effect of bacteriophage lambda infection on synthesis of groE protein and other Escherichia coli proteins. J. Bacteriol. 149:1050-1063.

9. Enquist, L., D. Tiemeier, P. Leder, R. Weisberg, and N. Sternberg. 1976. Safer derivatives of bacteriophage $\lambda \mathrm{gt} . \lambda \mathrm{C}$ for use in cloning of recombinant DNA molecules. Nature (London) 259: 596-598.

10. Goff, S. A., L. P. Casson, and A. L. Goldberg. 1984. Heat shock regulatory gene htpG influences rates of protein degradation and expression of the lon gene in Escherichia coli. Proc. Natl. Acad. Sci. USA 81:6647-6651.

11. Herendeen, S. L., R. A. VanBogelen, and F. C. Neidhardt. 1979. Levels of major proteins of Escherichia coli during growth at different temperatures. J. Bacteriol. 139:185-194.

12. Krueger, J. H., and G. Walker. 1984. groEL and dnaK genes of Escherichia coli are induced by UV irradiation and nalidixic acid in an $h t p R^{+}$- dependent fashion. Proc. Natl. Acad. Sci. USA 81:1499-1503.

13. Lai, B.-T., N. W. Chin, A. E. Stanek, W. Keh, and K. W. Lanks. 1984. Quantitation and intracellular localization of the $85 \mathrm{~K}$ heat shock protein by using monoclonal and polyclonal antibodies. Mol. Cell. Biol. 4:2802-2810.

14. Landman, O. E., H. T. Bausum, and T. S. Matney. 1962. Temperature-gradient plates for growth of microorganisms. J. Bacteriol. 83:463-469.

15. Lindquist, S. 1986. The heat shock response. Annu. Rev.
Biochem. 55:1151-1191.

16. Lloyd, R. G., and C. Buckman. 1985. Identification and genetic analysis of $s b c C$ mutations in commonly used $r e c B C s b c B$ strains of Escherichia coli K-12. J. Bacteriol. 164:836-844.

17. Maloy, S. R., and W. D. Nunn. 1981. Selection for loss of tetracycline resistance by Escherichia coli. J. Bacteriol. 145: 1110-1112.

18. Maurizi, M. R., P. Trisler, and S. Gottesman. 1985. Insertional mutagenesis of the lon gene in Escherichia coli: lon is dispensable. J. Bacteriol. 164:1124-1135.

19. Neidhardt, F. C., R. A. VanBogelen, and E. T. Lau. 1983 Molecular cloning and expression of a gene that controls the high-temperature regulon of Escherichia coli. J. Bacteriol. 153: $597-603$.

20. Neidhardt, F. C., V. Vaughn, T. A. Phillips, and P. L. Bloch. 1983. Gene-protein index of Escherichia coli K-12. Microbiol. Rev. 47:231-284.

21. Nover, L. (ed.). 1984. Heat shock response of eukaryotic cells, p. 7-12. Springer-Verlag, New York.

22. O'Farrell, P. H. 1975. High resolution two-dimensional electrophoresis of proteins. J. Biol. Chem. 250:4007-4021.

23. Phillips, T. A., R. A. VanBogelen, and F. C. Neidhardt. 1984. Ion gene product of Escherichia coli is a heat-shock protein. J. Bacteriol. 159:283-287.

24. Rothstein, R. J. 1983. One-step gene disruption in yeast. Methods Enzymol. 101:202-210.

25. Silhavy, T. J., M. L. Berman, and L. W. Enquist. 1984. Experiments with gene fusions. Cold Spring Harbor Laboratory, Cold Spring Harbor, N.Y.

26. Vieira, J., and J. Messing. 1982. The pUC plasmids, an M13mp7-derived system for insertion mutagenesis and sequencing with synthetic universal primers. Gene 19:258-268.

27. Walker, J. R. 1969. Escherichia coli ras locus: its involvement in radiation repair. J. Bacteriol. 99:713-719.

28. Winans, S. C., S. J. Elledge, J. H. Krueger, and G. C. Walker. 1985. Site-directed insertion and deletion mutagenesis with cloned fragments in Escherichia coli. J. Bacteriol. 161:12191221. 